\title{
Promoting voter registration: the effects of low-cost interventions on behaviour and norms
}

\author{
FELIX KÖLLE \\ Department of Economics, University of Cologne, Germany \\ TOM LANE \\ School of Economics, University of Nottingham Ningbo China \\ DANIELE NOSENZO \\ Luxembourg Institute of Socio-Economic Research (LISER), Luxembourg and School of Economics, University \\ of Nottingham, UK \\ CHRIS STARMER * \\ School of Economics, University of Nottingham, UK
}

\begin{abstract}
We report two studies investigating whether, and if so how, different low-cost interventions affect voter registration rates. Low-cost message-based interventions are increasingly used to promote target behaviours. While growing evidence shows that such 'nudges' often significantly impact behaviour, understanding of why interventions work or fail in particular contexts remains underdeveloped. In a natural field experiment conducted before the 2015 UK general election, we varied messages on a postcard sent by Oxford City Council to unregistered students encouraging them to join the electoral register. Our primary finding from the field study is that just one of our interventions - a reminder that people failing to register may be fined - has a significant positive impact. Offering small monetary rewards to register instead has a negative but insignificant effect. In a second study, using an online experiment we identify a particular mechanism explaining the influence of this intervention. Specifically, we show that our interventions have divergent effects on perceptions of the normative appropriateness of registering: emphasising that failing to register is punishable by law strengthened the perception that one ought to register, while offering monetary inducements for registering weakened the perception that doing so is an action already expected within society.
\end{abstract}

Submitted 20 November 2018; revised 20 February 2019; accepted 2 April 2019

* Correspondence to: Chris Starmer, School of Economics, University Park, University of Nottingham, NG7 2RD, UK. Email: chris.starmer@nottingham.ac.uk 


\section{Introduction}

Behavioural science is increasingly informing the use of low-cost interventions across a growing spectrum of public policy areas. The associated body of research is being built by - and is of interest to - both academics (e.g., Chetty, 2015; Hallsworth et al., 2017) and applied policy units (e.g. Behavioural Insights Team, 2010, 2011, 2012, 2016). Interventions often use subtle forms of influence or persuasion based on general motivational mechanisms, such as loss aversion, social information or social norms, and they are intended to systematically nudge people's behaviour towards some desired target at low cost for the policy-maker. ${ }^{1}$ These interventions, often based on mailers with carefully constructed messages, are used routinely to mobilize individuals by both private and public organisations to, for example, promote workers' productivity in firms (Hossain \& List, 2012), dissuade tax evasion (Hallsworth et al., 2017), and encourage debt repayment (Bursztyn et al., 2017), among other uses.

Our work is motivated by two stylised facts about these existing literatures. First, while there is now considerable evidence that low-cost interventions can sometimes have a significant impact on particular target behaviours, it seems that some types of intervention work well in some contexts and not others. Second, as yet there is very limited understanding of the underlying mechanisms that determine when and where a low-cost intervention will or will not work. In this paper, we examine the impact of different low-cost interventions in a field experiment and, via a follow-up online experiment, we test a potential mechanism - related to social norm compliance - to help explain patterns in the field data. As such, we see ourselves as contributing to an agenda for examining not only what works, but also what are the mechanisms that determine what works.

We do this in the context of a particular policy area: voter registration. In many countries - including the UK, where our study is conducted - any citizen wishing to vote must first register on the electoral roll. Registration in the UK is technically mandatory, and non-registration is punishable with an $£ 80$ fine. Yet, in the past two decades a substantial gap has emerged between

1 While the interventions we employ might be called 'nudges' by some, we do not use this terminology because a subset of our interventions may work, in part, via perceived impacts on financial incentives and so may be considered distinct from 'nudges' under some accepted definitions, including that of Thaler and Sunstein (2008). However, in the spirit of nudging, our interventions are low-cost (at least to the policy-maker - they may have 'emotional costs' for their recipients), easy to implement and, even when they involve a financial incentive element (as we will show), they work, at least in part, through psychological mechanisms that transcend the purely financial aspects. 
the numbers of eligible and registered voters, ${ }^{2}$ and it widened following the implementation of a legislative change in 2014: previously, all members of a household could be registered collectively, but the law now requires each person to register individually (Electoral Registration and Administration Act 2013). Besides any intrinsic benefits of wide democratic participation, high registration rates serve governmental interests insofar as the electoral roll has secondary uses such as fraud detection and jury recruitment. Employing low-cost behavioural interventions - if this can be shown to be effective - would be an attractive strategy in pursuit of this goal.

In the first part of this paper, we explore interventions that can be applied, at minimal financial expense, to encourage citizens to register to vote in elections. Specifically, we report the results of a field experiment run ahead of the 2015 UK general election in partnership with one such interested party, Oxford City Council (OCC), who sent postcards to students living in university accommodation encouraging them to register. Councils have a particular interest in discovering successful ways of targeting such students, as they represent a segment of society whose registration rates have been particularly affected by the recent legal change - previously, universities could register en masse all accommodated students, but the new law required them to register individually. While all of the postcards urged recipients not to miss their chance to vote, we systematically varied the precise content of their messages in order to test the effects of different persuasion strategies on registration rates.

Across six treatments, we implemented different types of interventions ranging from pure text/SMS-based reminders to register, to interventions including small financial incentives for registering. In a baseline treatment, the postcard that was sent to unregistered student voters simply encouraged them to register, without any additional message.

In three additional treatments, we explore the effectiveness of using small financial incentives for registering. In one treatment, we investigated the effectiveness of a threat of incurring a small monetary loss by adding a message highlighting the existence of the potential $£ 80$ fine for those who fail to register. Note, however, that subjects in all treatments were aware of the potential fine because this information had been sent to all subjects by the Council prior to our intervention. As such, we believe that this treatment is best understood as a reminder of the fine, although it is conceivable that our postcard raised the subjective probability that individuals assigned to being fined. In

2 See, for example, the 2016 report, Getting the 'Missing Millions' on to the Electoral Register: A Vision for Voter Registration Reform in the UK of the All Party Parliamentary Group on Democratic Participation, available at: https:/drive.google.com/file/d/0B8L818Sw8aKVRHJPQ19EQVZiTTQ/view (accessed May 2019). 
two further treatments, we tested the effectiveness of monetary rewards. In these treatments, students who registered early were offered entry into a lottery to win small cash prizes (of $£ 80$ ).

The use of monetary fines and rewards is an effective and widely applied practice in many areas of public policy. For example, emphasising the possibility of facing costly legal action has been found to exert a substantial positive effect in other policy domains, such as the enforcement of TV license registration (Fellner et al., 2013), debt repayment (Bursztyn et al., 2017), traffic violations (Lu et al., 2016) and tax returns (Kleven et al., 2011), although the evidence on the latter is rather mixed (for recent reviews of field experiments on tax compliance interventions, see Blumenthal et al., 2001; Slemrod et al., 2001; Hallsworth, 2014). Financial inducements, on the other hand, have been found to raise voter registration (John et al., 2015) and voter turnout (Panagopoulos, 2013), although in the latter case only when the inducements were sufficiently large (in John et al., 2015, a lottery involved large financial incentives - between $£ 1000$ and $£ 5000$ - and produced only a two percentage point increase in registration rates). ${ }^{3}$

Finally, we designed two additional treatments that did not involve any financial incentives but relied on purely psychological mechanisms to influence behaviour. In one treatment, we studied the role of reminders in encouraging registrations. Reminders have already been shown to be effective interventions in relation to voter registration (Bennion \& Nickerson, 2011), as well as in other contexts (e.g., Altmann \& Traxler, 2014). Thus, in this treatment, we asked students to provide their phone number so that they could be sent a reminder to register. In the other treatment, we wanted to test whether the likelihood to register increases if one has previously stated the intention to register. In this treatment, we asked students to report by text whether they intended to register. Similar interventions have been used in the context of voter turnout: asking subjects whether they intended to vote was found to have a positive impact on turnout by Greenwald et al. (1987, 1988), but not by Smith et al. (2003).

Our results show that emphasising the possibility of being fined yielded a large positive effect, with subjects exposed to this intervention having 1.6 times higher odds of registering than those in the baseline condition. In contrast, the prospect of financial gain had a negative but insignificant effect on registration. The two treatments based on purely psychological mechanisms had no measurable impact relative to the baseline.

3 More generally, there is now a large and diverse literature in economics showing that the threat of monetary loss may produce relatively strong responses, while the promise of monetary rewards may produce relatively weak ones (e.g., for reviews of this literature, see Balliet et al., 2011; van Lange et al., 2014; Nosenzo, 2016). 
In a follow-up online experiment using a different subject pool of UK students, we investigated a possible mechanism underlying the effectiveness of the fine reminder and the ineffectiveness of the lottery treatments: that is, their potentially contrasting effects on the perception of what constitutes socially appropriate behaviour in the context of voter registration. A growing body of recent economic research (e.g., Burks \& Krupka, 2012; Gächter et al., 2013; Krupka \& Weber, 2013; Banerjee, 2016; Gächter et al., 2017; Krupka et al., 2017; Barr et al., 2018) suggests that compliance with social norms drives behaviour across a wide range of contexts. Similarly, in the context of policy interventions aimed at reinforcing civic duties, as in the case of voter registration, interventions featuring small financial gains and losses may produce effects beyond those associated with the concrete monetary incentives, because of the way they interact with the very notion of 'civic duty'. In particular, we hypothesised that the fine and lottery treatments may have divergent effects on perceptions of the normative appropriateness of registering to vote: while highlighting the threat of a financial loss when failing to register may reinforce the perception that registering to vote is what one ought to do, offering potential financial gains may weaken the perception that registering is the socially appropriate thing to do.

Our results support these hypotheses. Using the incentivised norm-elicitation method of Krupka and Weber (2013), we found that exposing individuals to the fine intervention strengthened their perception that failing to register was socially inappropriate behaviour, while exposing them to the lottery intervention weakened the perception that registering was socially appropriate behaviour. Consequently, we propose that a change in the strength of the social norm relating to registration is a plausible putative mechanism that may partly explain why the fine intervention was successful while the lottery intervention was not. Indeed, a possible interpretation of our results is that - just as in some previous research (e.g., Frey \& Oberholzer-Gee, 1997; Ariely et al., 2009; Gneezy et al., 2011; Bowles \& Polania-Reyes, 2012) - monetary incentives crowded out individuals' intrinsic motivation to engage in socially constructive behaviour, and the adverse effect of the lottery intervention on the perceived social norm of registering may be partly behind this effect. Yet, to the best of our knowledge, this is the first paper that tests for the effects of monetary incentives on the perceived social appropriateness of certain actions directly.

Our study contributes to the literature regarding behavioural insights and low-cost interventions in public policy, as well as that demonstrating the importance of social norms for understanding human social behaviour. With regard to the case of voter registration, previous studies in economics and political science have analysed the effectiveness of different strategies to increase registration rates. For example, Nickerson (2007) and Bennion and 
Nickerson (2011) studied the effectiveness of sending emails to unregistered voters and found little evidence that this intervention could increase registration rates. On the other hand, face-to-face canvassing campaigns have been shown to have positive effects on voter registration (Nickerson, 2015; Braconnier et al., 2017). Relatedly, numerous studies have tested the efficacy of different persuasion strategies in promoting voter turnout. For example, more personalised get-out-the-vote contact (e.g., Gerber \& Green, 2000; Green et al., 2003), priming one's identity as a voter (Bryan et al., 2011) or applying social pressure on people to vote (e.g., Gerber et al., 2008, 2010; Davenport et al., 2010) all have positive effects on turnout (for a review of this literature, see Rogers et al., 2013).

We distinguish ourselves from these previous studies in several ways. First, while most previous studies employed purely non-monetary persuasion strategies, our study uses a unified experimental framework to assess the effectiveness of interventions involving positive and negative monetary incentives and benchmarks their effects against other strategies involving no financial incentives. Another novel and distinctive feature of our contribution is the combination of online and field experimental approaches, using the former to probe the underlying mechanisms that make specific field interventions more (or less) successful. By virtue of this approach, we believe we are the first to show that policy interventions using positive incentives may weaken perceptions of the normative appropriateness of target behaviours, whereas those relying on negative incentives may strengthen such perceptions. The insights from our paper may have significant policy implications that go beyond the case of voter registration. In particular, our results suggest that low-cost interventions are particularly effective when they are successful at enhancing the perceived social appropriateness of the targeted behaviour, while they might backfire if they inadvertently reduce the perceived appropriateness of it.

\section{Study I: field experiment on voter registration}

\section{Experimental design}

Our field experiment was designed to test the effectiveness of a set of low-cost interventions for raising voter registration rates ahead of the 2015 UK general election. The full design involved a set of six interventions including a baseline, two treatments involving small positive monetary incentives, one treatment reminding subjects of the possibility of being fined and two treatments involving non-monetary interventions. The interventions were implemented via adjustments to a message sent in a bulk, randomised mail-out (details below) to more than 7000 students living in the UK city of Oxford. 
We implemented one intervention reminding subjects of the threat of a monetary loss for failing to register. We did this by highlighting to subjects the truthful fact that they could be fined $£ 80$ if they did not register. This penalty is specified in UK law and, although in practice it is rarely enforced, it is referred to in standard materials that OCC use to promote voter registration. Note, however, that subjects in all treatments had been made aware of the potential fine, by the Council, prior to our intervention. As such, while we do not rule out the possibility that our postcard raised the subjective probability that some individuals assigned to being fined, our intervention can be best seen as a reminder of the possibility of being fined, rather than actually changing financial incentives.

We implemented two interventions involving the prospect of monetary rewards for registering. We did this with two treatments offering entry into a lottery to win cash prizes of the value of $£ 80$ for those who registered by a specific deadline. ${ }^{4}$ The two treatments differed only in that one attempted also to harness regret aversion (Loomes \& Sugden, 1982) by telling recipients that those who did not register would still be entered into the lottery and informed if they won, but would be unable to claim their prize. Regret aversion has previously been shown to affect entry decisions into lotteries (Zeelenberg \& Pieters, 2004; Gneezy, 2014; Imas et al., 2017).

In the last two interventions, we attempted to employ purely non-monetary persuasion strategies based on text messages. We did this in two treatments by asking students to provide their phone number so that they could be sent a reminder to register, or simply to report by text whether they intended to register.

Our interventions were transmitted via postcards, which OCC mailed to all unregistered voters living in student accommodation belonging to the University of Oxford and Oxford Brookes University on 9-10 March 2015, ahead of the 20 April deadline for voters to register in the general election. We collaborated with the Council to engineer the content of these postcards. While all of the postcards encouraged their recipients to register, the content of the messages they contained varied, allowing us to test the effects of the different persuasion strategies on registration rates.

All of the postcards were double sided (see Figure 1 for an image of the postcard used in our Baseline condition and Supplementary Appendix A (available online) for copies of the other postcards). The back simply contained the

4 Note that, although the Fine and Lottery treatments both employ the value of $£ 80$ as the possible loss or gain, the subjective probabilities subjects perceived of these eventualities occurring may have differed between the two treatments. This is not, therefore, an attempt to conduct a comparison between the effects of monetarily equivalent positive and negative incentives; rather, we are interested in comparing both against a baseline treatment featuring neither. 


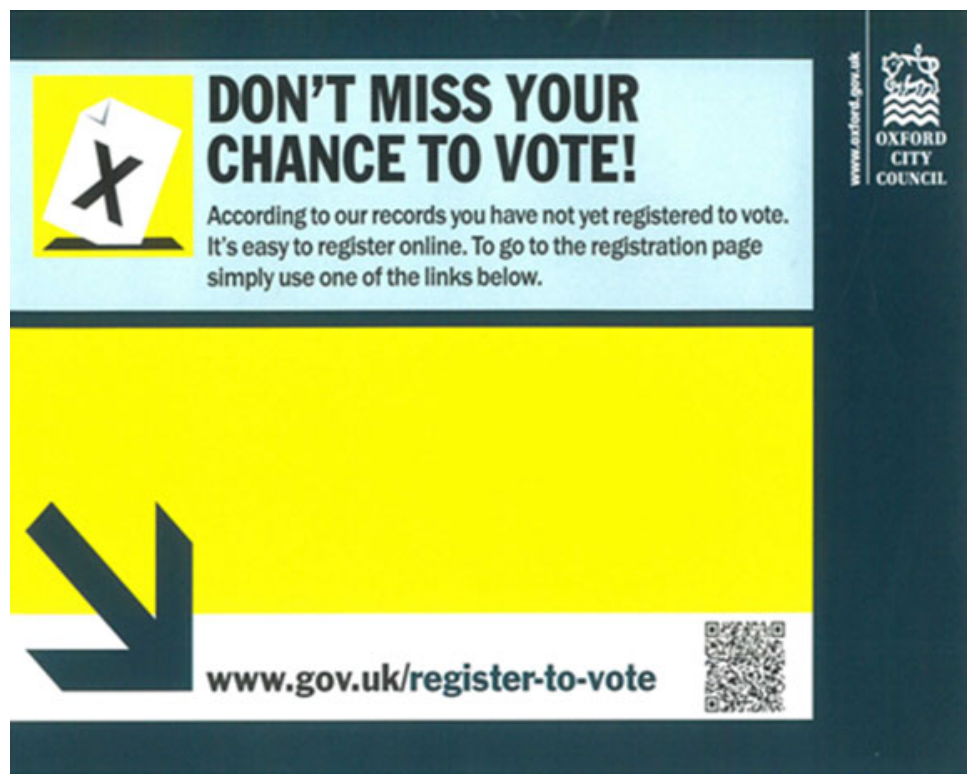

Figure 1. Postcard used in the Baseline treatment.

message, "IMPORTANT INFORMATION ABOUT YOUR RIGHT TO VOTE, OVERLEAF." The front featured the heading, "DON'T MISS YOUR CHANCE TO VOTE! According to our records you have not yet registered to vote. It's easy to register online. To go to the registration page simply use one of the links below." The bottom of this side contained the address of the government webpage for registering to vote and a QR code that would take recipients to the same page. These features were held constant across treatments. The postcards differed by treatment only according to the text included in a box below the heading on the front side.

\section{Treatments}

In the Baseline treatment, the box was left blank (Figure 1). This treatment therefore serves as a basis for comparison against the other treatments.

In the Fine treatment, the box contained the message: "If you don't register you could be fined $£ 80$."

In the Lottery treatment, the box contained the message: "If you register by 27 March 2015 you will be entered into a lottery to receive one of ten $£ 80$ prizes. Winning students will be notified in June 2015." In the Lottery Regret treatment, the box contained the message: "You have been entered into a lottery to receive one of ten $£ 80$ prizes. Winners will be notified in June 
2015 but you will only be able to claim your prize if you were already registered by 27 March 2015. If not your prize will go to another student."

In the Reminder treatment, the box contained the message: "Would you like us to send you a text reminder? If you do, please text 'reminder' to 60886." In the Intention treatment, the box contained the message: "We'd like to know if you are intending to register? If you are, please text 'myvote' to 60886." In both cases, texts were free of charge and this was clearly stated in the postcard.

\section{Assignment to treatment}

These four postcards were sent out on 9-10 March 2015 to 7679 voters who were still unregistered at the time and who lived in student accommodation buildings belonging to the University of Oxford and Oxford Brookes University. In order to minimise the likelihood of subjects seeing postcards belonging to treatments other than the one they were assigned to, we randomised assignment to treatment at the building level: all students living in a single building were assigned to the same treatment. For the University of Oxford, all students living in a single college were assigned to the same treatment. For Oxford Brookes University, all students living in a single hall of residence were assigned to the same treatment, with the exception that two very large halls were split into several geographically distinct units of assignment. This was to ensure balance between treatments in the proportion of subjects attending each university - we considered this important given the large demographic (particularly socioeconomic) differences between the student populations of each university. We further balanced treatment assignment by residence size (small and large) and age of college (ancient and modern) to account for other potential unobserved characteristics. ${ }^{5}$ The resulting sample sizes were as follows: Baseline $(n=1193)$; Fine $(n=1357)$; Lottery $(n=1250)$; Lottery Regret $(n=1317)$; Reminder $(n=1300)$; and Intention $(n=1262)$. See Supplementary Appendix B for further details on the assignment procedure and for a full breakdown of the colleges and halls assigned to each treatment.

\section{The dataset}

OCC provided us with anonymised data on registration rates amongst students residing in each college and hall at various points in time between January and April 2015. In particular, for each individual, our dataset specifies whether or

5 Despite our attempts to ensure balance in these dimensions, in Supplementary Appendix B, we show that some imbalances arose between our treatments. In our analysis of treatment effects, we will therefore include control variables to account for differences at the treatment level in university and hall/college characteristics. 
not they were registered on 2 January, 8 March (the day before the postcards of our experiment were sent out) and any subsequent day between 9 March and 20 April (the formal deadline to register to vote for the general election). The data also identify the treatment each individual was assigned to, their university affiliation (University of Oxford or Oxford Brookes University) and their hall or college. Other demographic data such as gender, age, etc., were not available to the Council.

\section{Results}

Figure 2 shows how registration rates differ between treatments over the entire period between the intervention and the formal deadline for registering. On a daily basis between 8 March and 20 April, Figure 2 displays the cumulative fraction, by treatment, of registered subjects amongst those who were unregistered on 2 January.

Pre-intervention registration rates (i.e. in the period 2 January-8 March) are very similar across all treatments; the fraction of registered subjects ranges between 0.076 and 0.093, showing no significant differences across treatments (see Table 1). This suggests that later treatment differences are unlikely to be driven by pre-existing differences between the subjects assigned to each intervention.

After our intervention (i.e., in the period 9 March-20 April), substantial differences emerge in the registration rates across treatments. On 20 April (the day of the registration deadline), the fraction of registered students amounts to 0.25 in Baseline, 0.31 in Fine, 0.21 in both Lottery treatments and 0.27 and 0.23 in the Reminder and the Intention treatments, respectively. Hence, compared to the case of a simple postcard, only the emphasis of (potential) negative monetary consequences had a positive effect on registration; registration rates in Fine are $24 \%$ higher than in Baseline. The introduction of (potential) positive monetary consequences, in contrast, had no positive effect on registration rates. While registration rates are initially similar to the ones in Baseline, they become lower towards the end of our observation period. Overall, the registration rate in our Lottery treatments is $16 \%$ lower than in Baseline. While based on the raw data the Reminder treatment seems to have a small positive effect on registration rates, our analysis below shows that this effect becomes negligible once controlling for demographic characteristics.

To further explore the observed treatment differences in registration rates, we run logistic regressions to model the individual-level registration decision. ${ }^{6}$ Our

6 Very similar results are obtained when using linear probability models instead of logistic regressions. 


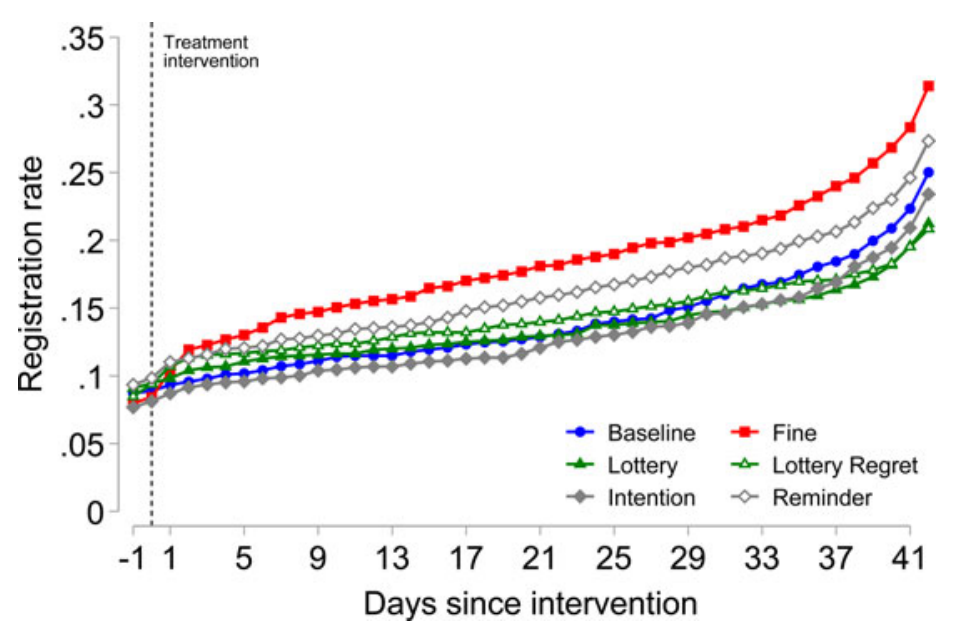

Figure 2. Cumulative registration rates by treatment.

Notes: Figure 2 shows, on a daily basis between 8 March and 20 April, the amount of registered students in the treated buildings as a fraction of all students in these buildings who had been unregistered on 2 January. The vertical dashed line at day 0 represents the day of our treatment intervention ( 9 March).

dependent variable is 1 or 0 depending on whether or not an individual has registered in a given period. As independent variables, we use dummies to represent the treatment to which an individual was assigned. To test the robustness of our results, in some of the models we include additional control variables. In particular, given the very different natures of the two universities that were included in our study, we also include a dummy variable for whether a student was affiliated with either Oxford Brookes University or University of Oxford. As further controls, we include: which of the two Oxford voting areas (general election constituencies) a given student resides in; the size of the residence unit they live in; and a 'modern' dummy, which takes value 0 if the college or hall in which they live is older than 100 years and value 1 otherwise. ${ }^{7}$ To correct for heteroscedasticity and potential dependency of observations within halls, we cluster standard errors by residence unit, which is the level of randomisation. ${ }^{8}$ The results of these regressions are reported in Table 1.

7 We included this dummy because we conjectured that there could be some difference in ethos or culture that could be relevant to the registration decision when comparing older and more newly established colleges.

8 That is, each college, hall, residence block and/or cross-college accommodation is treated as providing a cluster of observations, leading to a total of 82 clusters (see Supplementary Appendix B for further details). 
Table 1. The effects of treatments on registration rates.

\begin{tabular}{|c|c|c|c|c|}
\hline \multirow{2}{*}{$\begin{array}{l}\text { Dependent variable: registered ( } 1 \text { if yes, } 0 \\
\text { otherwise) }\end{array}$} & \multicolumn{2}{|c|}{$\begin{array}{l}\text { Before intervention } \\
\text { (2 January-8 March) }\end{array}$} & \multicolumn{2}{|c|}{$\begin{array}{l}\text { After intervention } \\
\text { (9 March-20 April) }\end{array}$} \\
\hline & Model (1) & Model (2) & Model (3) & Model (4) \\
\hline Fine & $\begin{array}{c}0.910 \\
(0.242)\end{array}$ & $\begin{array}{c}0.955 \\
(0.244)\end{array}$ & $\begin{array}{l}1.569^{* *} \\
(0.332)\end{array}$ & $\begin{array}{l}1.738 * * * \\
(0.353)\end{array}$ \\
\hline Lottery & $\begin{array}{c}1.046 \\
(0.252)\end{array}$ & $\begin{array}{c}1.086 \\
(0.192)\end{array}$ & $\begin{array}{c}0.709 \\
(0.241)\end{array}$ & $\begin{array}{c}0.707 \\
(0.224)\end{array}$ \\
\hline Lottery Regret & $\begin{array}{c}0.969 \\
(0.259)\end{array}$ & $\begin{array}{l}1.170 \\
(0.265)\end{array}$ & $\begin{array}{c}0.719 \\
(0.226)\end{array}$ & $\begin{array}{l}0.795 \\
(0.204)\end{array}$ \\
\hline Intention & $\begin{array}{c}0.871 \\
(0.299)\end{array}$ & $\begin{array}{c}0.842 \\
(0.266)\end{array}$ & $\begin{array}{c}0.945 \\
(0.203)\end{array}$ & $\begin{array}{c}1.002 \\
(0.208)\end{array}$ \\
\hline Reminder & $\begin{array}{l}1.079 \\
(0.256)\end{array}$ & $\begin{array}{l}1.019 \\
(0.195)\end{array}$ & $\begin{array}{l}1.139 \\
(0.281)\end{array}$ & $\begin{array}{l}1.013 \\
(0.196)\end{array}$ \\
\hline Odds of registering in Baseline & $\begin{array}{l}0.096 * * * \\
(0.018)\end{array}$ & $\begin{array}{l}0.118^{* * *} \\
(0.019)\end{array}$ & $\begin{array}{l}0.217^{* * * *} \\
(0.042)\end{array}$ & $\begin{array}{l}0.240^{* * *} \\
(0.045)\end{array}$ \\
\hline Wald test ( $p$-values) & & & & \\
\hline Lottery = Lottery Regret & 0.755 & 0.640 & 0.971 & 0.742 \\
\hline Reminder $=$ Intention & 0.508 & 0.522 & 0.285 & 0.956 \\
\hline Controls & No & Yes & No & Yes \\
\hline$n$ & 8397 & 8397 & 7679 & 7679 \\
\hline
\end{tabular}

Notes: Table 1 reports odds ratios from logistic regressions. A ratio greater than 1 implies a positive effect, whereas a ratio smaller than 1 implies a negative effect. The dependent variable indicates whether an individual registered within a given period. Models (1) and (2) include all subjects that were unregistered on 2 January. Models (3) and (4) include all subjects that participated in our experiment (i.e., who were not registered on 9 March, the day we sent out our postcards). Control variables include dummies for: student's university (Oxford Brookes University or University of Oxford); voting constituency; age of student hall (younger or older than 100 years); and size of the residence unit. Robust standard errors with $n=82$ clusters at the residence unit are reported in parentheses.

Significance levels: $* * p<0.05, * * p<0.01$.

Model (1) reports, for each treatment relative to Baseline (the omitted category), the factor changes in the odds of registering in the period before our intervention (i.e., between 2 January and $8 \mathrm{March}$ ). The sample includes all students in treated buildings who were unregistered on 2 January. In the Baseline treatment, the odds of registering in the pre-intervention period are 0.096 (i.e., there are expected to be approximately 10 unregistered students for each registered student in our benchmark condition). The odds of registering are very similar in the other treatments: in all cases, the factor changes in the odds are close to 1 and none of the treatment variables are significant (all $p$-values $>0.686$ ). Very similar results are obtained in model (2), where we include the additional control variables. While the magnitudes of the factor changes in odds of registering change slightly, all 
treatment dummies remain insignificant. This confirms that registration rates are indistinguishable across treatments in the pre-intervention period.

In model (3), we look at the effect of our different interventions after their implementation. The dependent variable now is whether an individual registered or not during the period between 9 March and 20 April, the day of the registration deadline. The sample includes all students in treated buildings who were still unregistered on 8 March (i.e., we drop those who registered before the intervention, since they did not receive the postcards that were sent out on 9 March). The treatment dummies therefore represent treatment differences in registration rates after the intervention. The odds of registering in Baseline are now 0.217. The higher baseline odds of registering in the post-intervention period relative to the pre-intervention period may reflect an impact of sending the postcard per se or a natural increasing trend in registrations as the deadline for the general election draws nearer. ${ }^{9}$

The Fine treatment increases the Baseline odds by a factor of 1.6 and the effect is significant at the 5\% level. This implies an expected ratio of more than 3:1 between unregistered and registered students in the Fine treatment (the odds of registering are $0.217 \times 1.569=0.340)$. In contrast, the Lottery and Lottery Regret treatments reduce the odds of registering relative to Baseline by factors of 0.709 and 0.719 , respectively, although the effects are not statistically significant ( $p=0.312$ and $p=0.295$, respectively). Furthermore, the two non-monetary treatments, Intention and Reminder, had no discernible effect on registration rates. The odds ratios are close to and not statistically different from 1 (both $p>0.748$ ). We believe that the reason for this result is that only 4 out of 1300 students requested a text reminder, and only 9 out of 1262 students texted their intention to register. This implies that only a small number of subjects were actually 'treated' by our interventions, and it is thus not very surprising that these treatments had no measurable impact relative to the baseline. Again, very similar results are obtained when including our control variables, as is shown in model (4). In Supplementary Appendix C, we further show that duration analysis, using a Cox proportional hazard model, yields qualitatively similar results for these post-intervention treatment differences.

\section{Study II: the effects of the interventions on social norms}

Our field experiment finds that highlighting the threat of a monetary fine is effective at encouraging registrations, while introducing the chance of a 
monetary gain is not. A number of possible mechanisms might contribute to an explanation of this pattern. For example, the fine reminder may have increased the subjective probability of suffering financial loss, and this, perhaps combined with some element of loss aversion, might explain the particular impact of the fine treatment. While we do not rule out such mechanisms being at work in our data, we explore a possible explanation that would potentially give rise to opposing impacts of the Fine and Lottery treatments. ${ }^{10}$ Specifically, we investigate the potentially different effects of these interventions on social norms (i.e., collectively recognised rules of behaviour that define which actions are viewed as socially appropriate) (Elster, 1989; Ostrom, 2000).

We conjecture that the Fine treatment may strengthen a pre-existing social norm that registering to vote is what one ought to do: emphasising that failing to register is against the law may reinforce one's perception that such behaviour is socially inappropriate. ${ }^{11}$ In contrast, the Lottery treatments may weaken that same social norm - the offer of money for registering may suggest to recipients that registering is not something already unconditionally demanded of them by society. If social norms influence registration behaviour, such alterations of subjects' perceptions of them could directly affect their decisions over registration. Indeed, the failure of the Lottery treatments is reminiscent of previous research showing that the introduction of economic incentives can crowd out people's intrinsic motivation to behave pro-socially. One of the possible mechanisms behind the ineffectiveness of financial rewards could be that the lottery weakens the social norm of registering, offsetting any positive effects of the monetary incentive.

\section{Experimental design and procedures}

To investigate this, we ran an online study, employing the social norm elicitation task pioneered by Krupka and Weber (2013). In this study, we first described to subjects the setting of our field experiment. We then exposed each subject to the postcard used in one of three treatments - Baseline, Fine and Lottery ${ }^{12}-$ and in

10 Recall that while monetary losses have a significant positive impact on registration rates (relative to baseline), there is some indication in our data that the impact of monetary gains may in fact be negative, as registration is lower under the Lottery treatments than under Baseline (though this is not significant).

11 There is some debate over whether social norms and laws are substitutes or whether laws directly shape norms; see, for instance, Posner (2009) and Benabou and Tirole (2011).

12 We only focus on one version of the Lottery treatments because, in the field experiment, the Lottery Regret treatment was statistically indistinguishable from the Lottery treatment and the Lottery treatment was easier to describe to subjects. 
each case measured the social norms they perceived pertaining to registration behaviour.

This study was run in June 2016, with subjects who were students at the University of Nottingham, recruited through the Online Recruitment System for Economic Experiments (ORSEE; Greiner, 2015), an online database of experimental participants. Thus, the subjects would have been demographically similar to those in the field experiment, but would not have been previously exposed to the postcards. ${ }^{13}$ In total $n=189$ subjects participated in the study: 65 were shown the Baseline postcard, 61 the Fine postcard, and 63 the Lottery postcard. The study was conducted using Qualtrics (Qualtrics, 2016), an online survey platform.

At the beginning of the experiment, subjects were told: "Imagine that the date is March 8, 2015. There is an upcoming General Election on May 7, and a local council wants to encourage people to register to vote before the deadline on April 20." They were further informed that the council is considering strategies to raise registration amongst students in university accommodation, where rates have been particularly low. They were then told that the council decides to send a card to every unregistered student living in university accommodation, and they were then presented with a picture of one of three cards. These were replicas of the postcards sent out to students in the Baseline, Fine and Lottery treatments (the only difference was that the cards were cropped to cut off the OCC logo).

Subjects were then asked to evaluate "how socially appropriate most people would think it would be for a student, having received this card, to register to vote or not to register to vote." Earlier in the instructions, we had defined social appropriateness as "behaviour that you think most people would agree is the 'correct' thing to do. Another way to think about what we mean is that if someone were to behave in a socially inappropriate way, then other people might be angry at them." 14

13 It was not possible to recruit the same participants from Study I again for Study II because we did not collect any personal information about the subjects who took part in Study I. For Study II, we therefore recruited subjects from a similar population (undergraduate students at another British university), and our inferences assume that norms are not too dissimilar between the populations used in the two studies. We do not think that this assumption is very strong given that student samples are fairly homogeneous, especially within a given country/culture (e.g., see Gächter, 2010). Another advantage of using a between-subject design (with different samples for Study I and Study II) is that we can circumvent the issue of order and spill-over effects that may arise in within-subject designs (for a discussion of this point in relation to norm-elicitation experiments, see D'Adda et al., 2016).

14 This follows the experimental instructions introduced by Krupka and Weber (2013). See Supplementary Appendix D for the experimental instructions and screenshots of the online survey. 
We then asked subjects to evaluate the social appropriateness of each action (register to vote, not register to vote) on a four-point scale, encompassing 'very socially appropriate', 'somewhat socially appropriate', 'somewhat socially inappropriate' and 'very socially inappropriate'. ${ }^{15}$ These evaluations were incentivised such that subjects were encouraged to coordinate on the social norm: we told subjects we would randomly select one of the two actions, and for this action, they would be eligible to receive a cash prize if their evaluation of its social appropriateness was the same as that chosen by the most other subjects. ${ }^{16}$

\section{Results}

To analyse the data, we follow Krupka and Weber (2013) in transforming the evaluations into numerical values. We assign evenly spaced values of -1 for the rating 'very socially inappropriate', -0.33 for the rating 'somewhat socially inappropriate', 0.33 for the rating 'somewhat socially appropriate' and 1 for the rating 'very socially appropriate'. We then calculate the mean ratings for each action by subjects exposed to each treatment. The results are displayed in Figure 3.

We find that, regardless of the treatment subjects are exposed to, registering to vote tends to be seen as highly appropriate behaviour, while failing to register is generally seen as inappropriate. However, there are also subtle but significant treatment differences in people's appropriateness judgements. In particular, subjects exposed to the Lottery treatment perceived registering to vote to be less appropriate than did those exposed to the Baseline treatment (two-tailed Fisher randomisation test, $p=0.012$ ). ${ }^{17}$ Moreover, failing to

15 Asking subjects to evaluate the appropriateness of all possible actions in the given scenario is standard procedure in studies following the methodology of Krupka and Weber (2013). In cases like ours, where there are only two possible actions (register to vote, not register to vote), the appropriateness rating given to one action may not be the inverse of the rating given to the alternative action. For instance, it is conceivable that participants could believe that both registering to vote and not registering to vote were very socially appropriate. Thus, it is necessary to measure treatment effects on the appropriateness of both actions.

16 As the study was very short and conducted online, we paid only one out of every eight subjects, determined retrospectively at random (subjects knew about this at the beginning of the experiment). Those chosen for payment received an automatic $£ 10$, plus a further $£ 30$ if their evaluation matched that of the most other subjects in their treatment. Although most subjects would not be paid, the study was still incentivised to a conventional level: all subjects had a 1/8 chance of receiving between $£ 10$ and $£ 40$ for an approximately 5 -minute task.

17 See Moir (1998) for a discussion of the randomisation test, and Kaiser and Lacy (2009) for information on the Stata command to apply it. In Study II, we correct $p$-values for testing multiple hypotheses for two interrelated dependent variables (the appropriateness of registering to vote and not registering to vote). For each dependent variable, we test Lottery versus Baseline and Fine 


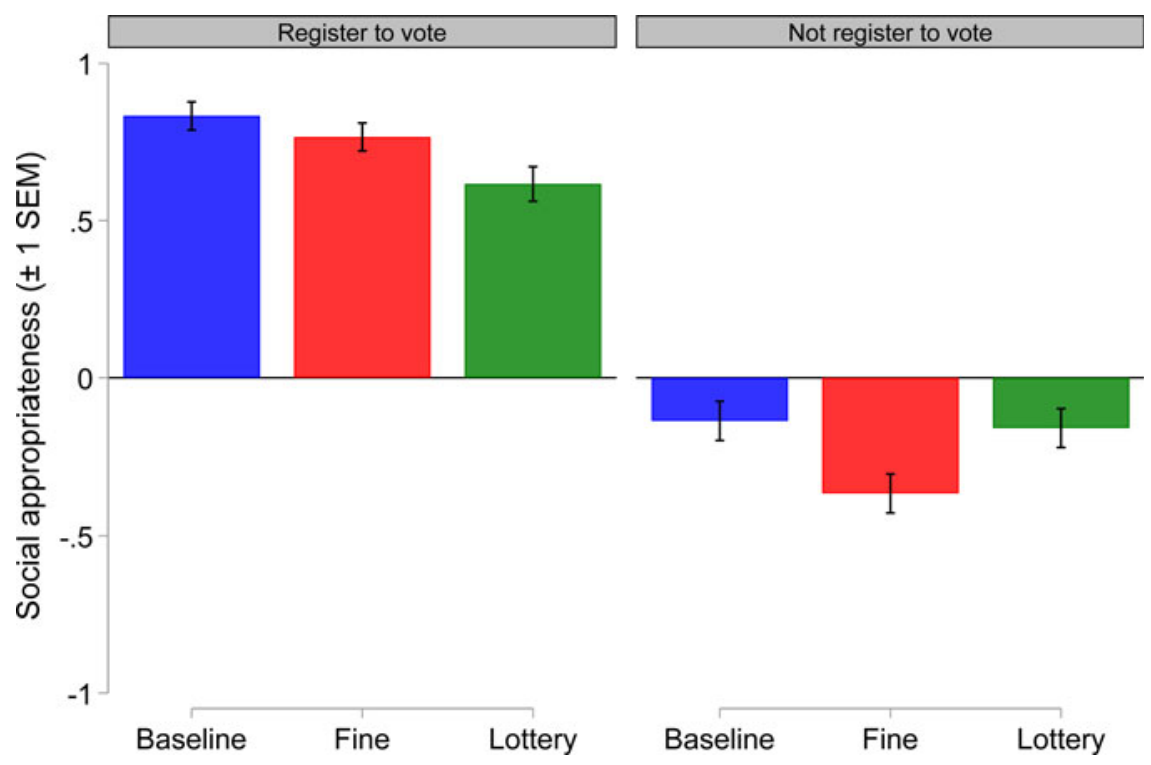

Figure 3. Social appropriateness of registration behaviour by treatment.

Notes: Figure 3 shows the mean appropriateness ratings assigned to each action (registering to vote, not registering to vote) by subjects exposed to the Baseline, Fine and Lottery postcards. Mean ratings are taken by assigning values of $-1,-0.33,0.33$ and 1 for the ratings 'very inappropriate', 'somewhat inappropriate', 'somewhat appropriate' and 'very appropriate', respectively, and averaging the values for each action for all participants exposed to a given treatment. Error bars indicate standard errors of the mean.

register to vote was perceived to be more inappropriate by subjects exposed to the Fine treatment than it was by those exposed to the Baseline treatment $(p=0.016)$. In contrast, we find no significant differences in the perceptions of appropriateness of registering between Fine and Baseline $(p=0.543)$, or the inappropriateness of not registering between Lottery and Baseline $(p=0.718)$.

Table 2 sheds light on how these treatment differences arise. It presents, for each treatment, the distribution of subjects' evaluations of the social appropriateness of each action. It shows that the lower perceived social appropriateness of registering under Lottery is driven by fewer subjects regarding registering as 'very socially appropriate' relative to Baseline $(50.8 \%$ versus $78.1 \%)$. We also see that the higher perceived social inappropriateness of failing to register in the 
Table 2. Distribution of social appropriateness evaluations.

\begin{tabular}{|c|c|c|c|c|}
\hline \multicolumn{5}{|c|}{ Appropriateness of registering to vote } \\
\hline & Very socially inappropriate & Somewhat socially inappropriate & Somewhat socially appropriate & Very socially appropriate \\
\hline Baseline & 1.6 & 0 & 20.3 & 78.1 \\
\hline Fine & 0 & 1.7 & 31.7 & 66.7 \\
\hline Lottery & 0 & 8.2 & 41.0 & 50.8 \\
\hline \multicolumn{5}{|c|}{ Appropriateness of not registering to vote } \\
\hline & Very socially inappropriate & Somewhat socially inappropriate & Somewhat socially appropriate & Very socially appropriate \\
\hline Baseline & 10.9 & 54.7 & 28.1 & 6.3 \\
\hline Fine & 25.0 & 58.3 & 13.3 & 3.3 \\
\hline Lottery & 9.8 & 60.7 & 23.0 & 6.6 \\
\hline
\end{tabular}

Notes: Table 2 displays, for each treatment, the distribution of social appropriateness evaluations. The numbers are the percentages of subjects who evaluated registering to vote (top panel) or not registering to vote (bottom panel) as very socially inappropriate, somewhat socially inappropriate, somewhat socially appropriate or very socially appropriate. 
Fine treatment is driven by more subjects regarding not registering as 'very socially inappropriate' relative to Baseline $(25.0 \%$ versus $10.9 \%)$ and by fewer regarding it as 'somewhat socially appropriate' (13.3\% versus $28.1 \%$ ).

To summarise the results of Study II, we find that in all treatments subjects perceived that there exists a social norm of registering to vote. Subjects exposed to the Fine treatment perceived a relatively stronger stigma for violating this norm: failing to register is seen as particularly inappropriate when the norm is supported by penalties against violators. By contrast, subjects exposed to the Lottery treatment perceived a weaker normative injunction to follow the norm. We find this effect intuitive: offering monetary rewards for taking behaviours that are already demanded by the norm sends mixed signals about the strength of the normative prescription. Moreover, we find that each type of incentive only affects the perception of the appropriateness of the behaviour that is explicitly targeted by the incentive: penalties against violators influence the inappropriateness of violations, while rewards for compliant individuals influence the appropriateness of compliance.

Overall, our results suggest that emphasising the fine for failing to register strengthens the social norm against such behaviour, while offering monetary incentives for successfully registering weakens the social norm demanding such behaviour. Given the strong evidence from previous studies (see 'Introduction' section) that social norms influence economic behaviour, we propose that these normative effects explain at least part of the success of the Fine treatment and the ineffectiveness of the Lottery treatments.

\section{Conclusion}

Low-cost interventions are increasingly being used to promote a wide range of behaviours targeted by different messages. While a growing body of evidence shows that such interventions often significantly impact behaviour, understanding of why they work or fail in particular contexts remains underdeveloped. In this paper, we investigated whether - and if so why - different low-cost interventions affect voter registration rates. A unique feature of our study is that it combines two types of experiment: a field experiment to measure which persuasion strategy is most effective in raising registrations; and an online experiment to investigate possible reasons why different strategies may trigger different behavioural responses.

Our field experiment shows that highlighting to citizens the possibility of being fined for failing to register is an effective strategy for public bodies to use. The effect we identified was not only statistically significant, but also of a substantial magnitude: having the fine emphasised raised the odds of registering by a factor of 1.6 , from 0.22 in the Baseline condition to 0.34 . 
In contrast, we find no evidence that offering small financial inducements for registration is an effective strategy. We speculate that the lack of success of our Lottery treatments may represent another case of economic incentives crowding out people's intrinsic motivation to behave in socially constructive ways (e.g., Frey \& Oberholzer-Gee, 1997; Ariely et al., 2009; Gneezy et al., 2011; Bowles \& Polania-Reyes, 2012). We note that, in this respect, our study's results differ from those of John et al. (2015), who also offered entry into a cash lottery as a reward for registering to vote in the UK. They found a small (approximately 2\%) but significant positive effect of monetary rewards on registration rates. A possible explanation for the contrast in results is that the maximum winnings offered by John et al. (2015) were much larger than ours (between $£ 1000$ and $£ 5000$ ). Their large material incentives may well have been enough to produce a positive effect, even if they had to overcome a crowding out effect (Bowles \& Polania-Reyes, 2012). A tentative conclusion could then be that, when offering cash for behaviours where there is a danger of crowding out intrinsic motivations, one must 'pay enough or don't pay at all' (Gneezy \& Rustichini, 2000a). This would also be consistent with Panagopoulos (2013), who found that financial inducements raised voter turnout, but only once they were sufficiently large.

Our online experiment suggests a possible explanation for the contrasting effects of highlighting negative monetary incentives and introducing positive monetary incentives on voter registration rates: that is, because of their differential effects on relevant social norms. In fact, we believe our study is the first to directly measure the effects of financial incentives on the social appropriateness of any type of behaviour. Our results show that emphasising the fine strengthens the perception that failing to register is socially inappropriate, while offering money for registering weakens the perception that registering is socially appropriate - and we conjecture that this weakening could be behind a crowding out of intrinsic motivations. Note that the effectiveness of our fine treatment contrasts with the results of Gneezy and Rustichini (2000b), who found that parents were more likely to be late in picking up their children when their day-care centres threatened to fine them for doing so, plausibly because the fine weakened the social norm that parents should turn up on time. Why in our case highlighting the fine instead is found to strengthen the social norm of registering may be because it is administered by a public body and based on existing law.

Taken together, we interpret our results as evidence that social norms may be one determinant of voter registration. This would be consistent with other recent experimental literature pointing to the importance of social norms as drivers of a wide range of behaviours (e.g., Burks \& Krupka, 2012; Gachter et al., 2013; Krupka \& Weber, 2013; Banerjee, 2016; Kimbrough \& 
Vostroknutov, 2016; Krupka et al., 2017; Barr et al., 2018). A key novel contribution of our study in relation to this literature is in identifying the potentially important role of social norms in determining the effectiveness of different types of low-cost interventions. As such, we believe that the insights from our paper have important policy implications that go beyond the case of voter registration. In particular, our results suggest that low-cost interventions are particularly successful in nudging individuals towards a target behaviour when they strengthen the social norms that underlie that target. In contrast, interventions might backfire when they weaken the social norms that sustain the target behaviour.

These findings highlight the importance for policy-makers to anticipate the potential interactions between particular interventions designed to target specific behaviours and the social norms that regulate those same behaviours. While it may be difficult to surmise, ex ante, whether a particular intervention may strengthen or weaken a social norm, one of the contributions of our study is to show that there are simple tools, such as our norm-elicitation experiment, that are available to researchers and policy-makers alike and that can be used to measure the impact of policy interventions on underlying social norms before a particular behavioural intervention is rolled out in the field.

\section{Supplementary Material}

To view supplementary material for this article, please visit https:/doi.org/10. 1017/bpp.2019.10

\section{Acknowledgements}

This work was supported by the Economic and Social Research Council (grant numbers ES/K002201/1, ES/P008976/1) and by the Centre for Decision Research and Experimental Economics within the University of Nottingham's School of Economics. The research was done in collaboration with Oxford City Council's Electoral Services team, in particular Suzette Starmer and Martin John. We received important assistance in Nottingham from Suzanne Robey. We received helpful input during the course of the project from seminar audiences at Nottingham and from Abigail Barr, Robin Cubitt, Matthias Dahm, Markus Eberhardt, Gianni De Fraja, Todd Rogers and Konstantinos Tatsiramos.

\section{References}

Altmann, S. and C. Traxler (2014), 'Nudges at the Dentist', European Economic Review, 72, 19-38. Ariely, D., A. Bracha and S. Meier (2009), 'Doing good or doing well? Image motivation and monetary incentives in behaving prosocially', The American Economic Review, 99(1): 544-555. 
Balliet, D., L. B. Mulder and P. A. Van Lange (2011), 'Reward, punishment, and cooperation: a metaanalysis', Psychological bulletin, 137(4): 594.

Banerjee, R. (2016), 'On the interpretation of bribery in a laboratory corruption game: Moral frames and social norms', Experimental Economics, 19(1): 240-267.

Barr, A., T. Lane and D. Nosenzo (2018), 'On the social inappropriateness of discrimination', Journal of Public Economics, 164, 153-164.

Behavioural Insights Team (2010), Applying behavioural insight to health. London: Cabinet Office.

Behavioural Insights Team (2011), Behaviour change and energy use. London: Cabinet Office.

Behavioural Insights Team (2012), Applying behavioural insights to reduce fraud, error and debt. London: Cabinet Office.

Behavioural Insights Team (2016), Applying behavioural insights to regulated markets. London: Cabinet Office.

Benabou, R. and J. Tirole (2011), Laws and norms (No. w17579). National Bureau of Economic Research.

Benjamini, Y. and Y. Hochberg (1995), 'Controlling the false discovery rate: a practical and powerful approach to multiple testing', Journal of the Royal Statistical Society. Series B (Methodological), 289-300.

Bennion, E. A. and D. W. Nickerson (2011), 'The cost of convenience: An experiment showing e-mail outreach decreases voter registration', Political Research Quarterly, 64(4): 858-869.

Blumenthal, M., C. Christian, J. Slemrod and M. G. Smith (2001), 'Do normative appeals affect tax compliance? Evidence from a controlled experiment in Minnesota', National Tax Journal, $125-138$.

Bowles, S. and S. Polania-Reyes (2012), 'Economic incentives and social preferences: substitutes or complements? Journal of Economic Literature, 50(2): 368-425.

Braconnier, C., J. Y. Dormagen and V. Pons (2017), 'Voter registration costs and disenfranchisement: experimental evidence from France', American Political Science Review, 111(3): 584-604.

Bryan, C. J., G. M. Walton, T. Rogers and C. S. Dweck (2011), 'Motivating voter turnout by invoking the self', Proceedings of the National Academy of Sciences, 108(31): 12653-12656.

Burks, S. V. and E. L. Krupka (2012), 'A multimethod approach to identifying norms and normative expectations within a corporate hierarchy: Evidence from the financial services industry', Management Science, 58(1): 203-217.

Bursztyn, L., S. Fiorin, D. Gottlieb and M. Kanz (2017), 'Moral Incentives in Credit Card Debt Repayment: Evidence from a Field Experiment', Journal of Political Economy, forthcoming.

Chetty, R. (2015), 'Behavioral economics and public policy: A pragmatic perspective', The American Economic Review, 105(5): 1-33.

D'Adda, G., M. Drouvelis and D. Nosenzo (2016) 'Norm Elicitation in Within-Subject Designs: Testing for Order Effects', Journal of Behavioural and Experimental Economics, $62,1-7$.

Davenport, T. C., A. S. Gerber, D. P. Green, C. W. Larimer, C. B. Mann and C. Panagopoulos (2010) 'The enduring effects of social pressure: Tracking campaign experiments over a series of elections', Political Behavior, 32(3): 423-430.

Elster, J. (1989), 'Social Norms and Economic Theory', The Journal of Economic Perspectives 3(4): 99-117.

Fellner, G., R. Sausgruber and C. Traxler (2013), 'Testing enforcement strategies in the field: Threat, moral appeal and social information', Journal of the European Economic Association, 11(3): 634-660.

Frey, B. S. and F. Oberholzer-Gee (1997), 'The cost of price incentives: An empirical analysis of motivation crowding-out', The American Economic Review, 87(4): 746-755.

Gächter, S. (2010), '(Dis)advantages of student subjects: What is your research question?' Behavioural and Brain Sciences 33, 92. 
Gächter, S., L. Gerhards and D. Nosenzo (2017), 'The importance of peers for compliance with norms of fair sharing', European Economic Review, 97: 72-86

Gächter, S., D. Nosenzo and M. Sefton (2013), 'Peer effects in pro-social behaviour: Social norms or social preferences? Journal of the European Economic Association, 11(3): 548-573.

Gerber, A. S. and D. P. Green (2000), 'The effects of canvassing, telephone calls, and direct mail on voter turnout: A field experiment', American Political Science Review, 94(3): 653-663.

Gerber, A. S., D. P. Green and C. W. Larimer (2008), 'Social pressure and voter turnout: Evidence from a large-scale field experiment', American Political Science Review, 102(1): 33-48.

Gerber, A. S., D. P. Green and C. W. Larimer (2010), 'An experiment testing the relative effectiveness of encouraging voter participation by inducing feelings of pride or shame', Political Behavior, 32(3): 409-422.

Gneezy, U. and A. Rustichini (2000a), 'Pay enough or don't pay at all', The Quarterly Journal of Economics, 115(3): 791-810.

Gneezy, U. and A. Rustichini (2000b), 'A fine is a price', The Journal of Legal Studies, 29(1): 1-17.

Gneezy, U., S. Meier and P. Rey-Biel (2011), 'When and why incentives (don't) work to modify behavior', The Journal of Economic Perspectives, 25(4): 191-209.

Gneezy, U. (2014), Incentives and behavior change - Put your money to work. Conference Presentation. http://www.behaviourworksaustralia.org/V2/wp-content/uploads/2014/11/ Incentives-and-behavior-change-sep-14-13-short.pdf

Green, D. P., A. S. Gerber and D. W. Nickerson (2003), 'Getting out the vote in local elections: Results from six door-to-door canvassing experiments', The Journal of Politics, 65(4): 1083-1096.

Greenwald, A. G., C. G. Carnot, R. Beach and B. Young (1987), 'Increasing voting-behaviour by asking people if they expect to vote', Journal of Applied Psychology, 72(2): 315-318.

Greenwald, A. G., M. R. Klinger, M. E. Vande Kamp and K. L. Kerr (1988), The self-prophecy effect: Increasing voter turnout by vanity-assisted consciousness raising. Unpublished manuscript, University of Washington.

Greiner, B. (2015) 'Subject pool recruitment procedures: organizing experiments with ORSEE', Journal of the Economic Science Association, 1(1): 1-12.

Hallsworth, M. (2014), 'The use of field experiments to increase tax compliance', Oxford Review of Economic Policy, 30(4): 658-679.

Hallsworth, Michael, et al. (2017) 'The behavioralist as tax collector: Using natural field experiments to enhance tax compliance', Journal of Public Economics, 148,14-31.

Hossain, T and J. A. List (2012) 'The Behavioralist Visits the Factory: Increasing Productivity Using Simple Framing Manipulations, Management Science, 58 (12)

Imas, A., D. Lamé and A. J. Wilson (2017), Preference Reversals Between One-Shot and Repeated Decisions: The Case of Regret". Unpublished manuscript available at: http://www.aleximas. $\mathrm{com} / \mathrm{s} /$ PrefReversalsRegret-1.pdf.

John, P., E. MacDonald and M. Sanders (2015), 'Targeting voter registration with incentives: A randomized controlled trial of a lottery in a London borough', Electoral Studies, 40, 170-175.

Kaiser, J. and M. G. Lacy (2009), 'A general-purpose method for two-group randomization tests', Stata Journal, 9(1): 70.

Kimbrough, E.O., and A. Vostroknutov. 2016. 'Norms Make Preferences Social', Journal of the European Economic Association 14, 608-638.

Kleven, H. J., M. B. Knudsen, C. T. Kreiner, S. Pedersen and E. Saez (2011), 'Unwilling or unable to cheat? Evidence from a tax audit experiment in Denmark', Econometrica, 79 (3): 651-692.

Krupka, E. L. and R. A. Weber (2013), 'Identifying social norms using coordination games: Why does dictator game sharing vary? Journal of the European Economic Association, 11(3): 495-524.

Krupka, E. L., S. Leider and M. Jiang (2017), 'A meeting of the minds: informal agreements and social norms', Management Science, 63(6): 1708-1729 
Loomes, G. and R. Sugden (1982), 'Regret theory: An alternative theory of rational choice under uncertainty', The Economic Journal, 92(368): 805-824.

Lu, F., J. Zhang and J. Perloff (2016), 'General and specific information in deterring traffic violations: Evidence from a randomized experiment', Journal of Economic Behavior \& Organization, 123, 97-107.

Moir, R. (1998), 'A Monte Carlo analysis of the Fisher randomization technique: reviving randomization for experimental economists’, Experimental Economics, 1(1): 87-100.

Nickerson, D. W. (2007), 'Does email boost turnout', Quarterly Journal of Political Science, 2(4): 369-379.

Nickerson, D. W. (2015), 'Do Voter Registration Drives Increase Participation? For Whom and When? Journal of Politics, 77(1).

Nosenzo, D. (2016), Employee incentives: Bonuses or penalties? IZA World of Labor.

Ostrom, E. 2000. 'Collective action and the evolution of social norms', The Journal of Economic Perspectives 14(3): 137-158.

Panagopoulos, C. (2013), 'Extrinsic rewards, intrinsic motivation and voting', The Journal of Politics, 75(01): 266-280.

Posner, E. A. (2009), Law and social norms, Harvard University Press.

Qualtrics (2016), Data for this paper was generated using Qualtrics software. Copyright @ [2016] Qualtrics. Qualtrics and all other Qualtrics product or service names are registered trademarks or trademarks of Qualtrics, Provo, UT, USA. http://www.qualtrics.com

Rogers, T., C. R. Fox and A. S. Gerber (2013), 'Rethinking why people vote', The behavioural Foundations of Public Policy, 91.

Slemrod, J., M. Blumenthal and C. Christian (2001), 'Taxpayer response to an increased probability of audit: evidence from a controlled experiment in Minnesota', Journal of Public Economics, 79(3): 455-483.

Smith, J. K., A. S. Gerber and A. Orlich (2003), 'Self-Prophecy Effects and Voter Turnout: An Experimental Replication', Political Psychology, 24(3): 593-604.

Thaler, R. H. and C. R. Sunstein (2008), Nudge: Improving Decisions About Health, Wealth, and Happiness, Yale University Press.

Van Lange, P. A., B. Rockenbach and T. Yamagishi (Eds.). (2014), Reward and punishment in social dilemmas, Oxford University Press.

Zeelenberg, M. and R. Pieters (2004), 'Consequences of regret aversion in real life: The case of the Dutch postcode lottery', Organizational Behaviour and Human Decision Processes, 93(2): $155-168$. 